\title{
Explore the Human-based Teaching for the Professional Course of Materials Science and Engineering
}

\author{
Yiping Zhao, Li Chen \& Yufeng Zhang \\ Tianjin Key Laboratory of Fiber Modification and Functional Fiber \\ School of Materials Science and Chemical Engineering \\ Tianjin Polytechnic University \\ Tianjin 300160, China
}

Tel: 86-22-2452-8054 E-mail: yipingzhao@tjpu.edu.cn

The research is supported by the Higher Education Teaching Reform Project of Tianjin Polytechnic University.

\begin{abstract}
As viewed from two sides such as teacher and student, in this article, we explore the human-based teaching reform for the college professional course of materials Science and Engineering, point out the qualities and conditions that professional teacher should possess in the process of human-based teaching reform of professional course and the teaching measures and methods that they should adopt, analyze the responsibilities that students who are the main bodies of professional teaching should assume in the human-based teaching of professional course.
\end{abstract}

Keywords: Materials professional course, Human-based teaching, Teacher, Student

The human-based education is the education that abounds in humanity, more notices the human than things, and takes human interior demands, initial spirit and individual development as great intention, and it has active meanings to promote students to enhance their qualities and comprehensive developments.

The development of materials industry can not leave the talents of materials specialty with high qualities, and the teaching in materials specialty has important functions to cultivate professional materials science and technology talents with high qualities. The human-based teaching reform of materials professional course is the important content in the teaching reform of materials specialty, and it is also the demand to cultivate professional talents in materials specialty needed by the times. This task needs to be ensured by the big teaching environment of human-based teaching management system and the human-based teaching main bodies (teacher and student).

\section{The human-orientation of teachers' school}

The main body of professional course teaching is student, but teacher has leading function in the teaching process, and the human-orientation of teachers' school has key function to actualize the human-base teaching of professional course.

\subsection{Strengthening the human-oriented service consciousness}

The learner-oriented modern education idea is the concrete embodiment of people-oriented strategic idea in the teaching of professional course. The human-based teaching of materials professional course needs teacher strengthen the human-oriented service consciousness, emphasizes student-orientation in teaching course and result, takes students as teaching main body and center, respects students' human natures and humanisms, notices students' benefits, demands and developments. Teachers should not only teach students "learn", but teach them "can study". Teachers should not only teach students learn some professional knowledge, but also let them grasp the study ability for life. Teachers should not only impart students knowledge, but also lead students innovate, teach students be upright persons, edify them cooperation and dedication.

\subsection{Strengthening teachers' qualities and abilities}

In the teaching of materials professional course, teacher and student have strong character of mutual participation, and teacher's qualities and abilities directly influence student's human-based concept and integrated ability. "Words are the voice of the mind, and feelings move in meanings and act in faces". Teachers first should devote the specialty, or else, they are difficult to take delight in talking about and have expressions with smiles, so they are difficult to obtain students' respects and loves. Second, the human-based teaching method is decided by teachers' professional abilities, teaching arts and techniques. As the teacher of materials specialty, he should possess profound theoretic knowledge, strong practical technology, timely industry and professional follows in the materials specialty, and he can give students intuitionist impact from the specialty view, produce the effects of image, and make them understand the basic 
professional qualities and abilities that one qualified materials talent should possess, and inspire students' study pertinence, enthusiasm and intention.

On the other hand, teachers' moral qualities, humanistic sentiment, words and deeds also directly influence students' individual developments. The professional course teachers should learn to how to exert feeling teaching, continually perfect them, and lead students to explore scientific profound mystery with active passions. First, teachers are required to learn using smile teaching, close teacher-student relationship, eliminate feeling gulf, flourish classroom atmosphere through smile, and make students really happily study professional knowledge. Second, teachers should be encouraged to exert their advantages and fully utilize hortative language to inspire students' study interests and enthusiasms.

\subsection{Enriching the contents of classroom teaching}

The setup of teaching content of materials specialty should be embodied in teaching materials and courseware. Abundant teaching contents are the headspring to study specialty for students, and are also one important measure to inspire students' study interests and enthusiasms.

In recent years, with the quick development of materials science and technology, the professional contents are renovated frequently. When teachers choose teaching materials, they should combine traditional professional theories with modern new technologies organically, and ensure the close combination of teaching contents and students' specialty and social demands. Taking the professional course of macromolecule materials machining as an example, the traditional and continually outspread machining craftwork theory should be fixedly grasped by students, and the craftwork methods that have been washed out should not be introduced, and teachers should fully use the practical opportunities or other approaches such as consulting network or science and technology literatures to grasp and absorb some new craftworks and new equipments that can not be found in book, and impart the knowledge to students. In a word, the selection and enrichment of teaching contents is a hard work which needs teachers read professional books and literatures when they prepare for lessons and emphasize daily accumulations and absorb and re-understand new technologies.

At present, most course teachings of materials specialty adopt multimedia school, which requires teachers possess large information to make the courseware that is easily understood and grasped with innovations. For example, in the instruction process of craftwork lesson, teachers can introduce some movie materials or pictures about the aspect of production arts and crafts into the courseware, which can be easily learned and understood and inspire the study atmosphere in the classroom.

\subsection{Reforming the mode of classroom teaching}

For the classroom teaching method, teachings should transform form single knowledge disseminator to course governor. The teachers' functions should be mainly embodied in confirming teaching objective, evaluating teaching resource and environment, confirming the sequence of course implementation, checking the feasibility of course plan and constituting the implementation plan of course. The professional course teachers should more emphasize the strategy organically combining research teaching with research study, take students as the center, and let students obtain knowledge in solving problems by the scientific and research mode under the indirection of teachers.

On the other hand, teachers should introduce scientific research into the teaching process to some extent, and drive the cultivations of students' thinking abilities and scientific research abilities. In the prelection, teachers should organically combine professional theoretic knowledge with scientific research activities, let students grasp professional knowledge and technologies and know the methods and measures of scientific research, and cultivate students' innovational consciousness and abilities in the atmosphere full of scientific research mysteries.

\subsection{Actualizing opening classroom teaching system}

To actualize the human-based teaching of professional course, teachers should take the classroom as an opening system, take them as the main bodies to develop and manage the course recourse, and convenient for students to look after more opportunities of resources and exterior supports. For example, not only course teachers, but experts and practice persons outside the college, even other students (schoolmates can study each other in the communication, or obtain resources through modern information measures) can teach students.

\subsection{Strengthening the practical teaching}

The human-based teaching of materials specialty course can not leave human-based practice. To cultivate students' practical abilities and innovational spirits, in the experimental teaching part, single validating experiment should be reduced possibly, and the experiment with "three characters" including integration, design and research to evaluate the comprehensive performance of materials that are independently designed and prepared by students should be advocated. The comprehensive experiment can test and strengthen students' comprehensive knowledge and course knowledge relative to the course, implement comprehensive training and cultivation to students' knowledge, abilities and qualities. The designed experiment can make students design experiment plan, confirm experiment method, choose experiment equipments, study out operation procedure, complete experiment and analyze and disposal the experiment result 
according to appointed experiment intention and conditions and under teachers' directions. The research and exploring experiment can make students implement trainings with research and exploring characters aiming at certain one or some selected research objectives in teachers' research domain or selected subject direction. After the experiment is completed, students can also comprehensively know the relationships among composing, craftwork and performance for certain one system materials through communication. In the experiment, through materials consultation, communication and thinking, students can find the method to solve the problem, and realize more truth and inspire innovational thinking through summarization and more profound thinking. The facts have proved that large of experiments with "three characters" can make students strengthen the professional theoretic knowledge what they learn, and feel that the professional experiment is not the simple and mechanical recurrence no longer, but the space with comparative challenges and exertions, and accordingly inspire their experiment interests and innovational desires, and strengthen their comprehensive analysis ability and the ability to solve problems.

The practice of materials specialty is the necessary stage to cultivate professional talents of materials with high qualities. Therefore, various practice resources should be fully utilized, and the stable professional practical teaching base should be established to extend practice view.

\subsection{Emphasizing the individual difference of students}

The individuation education of professional course should have pertinence and can not use one standard to measure all students, and use one method to apply teaching, and one mode to cultivate all students. Teachers should adopt the classification direction and layer teaching method to teach students according to their different individual differences, interests, abilities and characters. For example, the course checking system should embody human-orientation and actualize the human-orientation and diversity for the checking and evaluation system. To notice and envisage students' differences of born abilities, teachers should combine students' study attitudes with study effects, set eyes on every student's advancement and development, be good at find their blink points, and implement different evaluations aiming at every student's different situation.

\subsection{Establishing good teacher-student relationship}

The good teacher-student relationship is the base to promote teachers and students' advancements. For the study of professional course in college, good teacher-student relationship is very important to inspire students study enthusiasms. In the human-based teaching process of materials specialty, the professional course teachers should bring pure-hearted hears, and play multiple degrees such as friend and teacher to press close to students, know their demands, channel their puzzles and solve their difficulties. Of course, the communication between heart and heart can not be accomplished in an action, teachers should exert a subtle influence on students by the mode of "salutary influence of education, moisten silently" in the teaching process.

\section{The human-orientation of students' study}

Students are the main body of teaching, and except for above teacher factor, students' cooperation is very pivotal to decide whether the human-based teaching of professional course can be successfully actualized.

\subsection{Correcting the study attitude for professional course}

Indubitably, to confirm study requirement and correct study attitude is the key to cultivate undergraduates to be talents. Only undergraduates have specific study objective, upright study attitude, full study enthusiasm and strong learn desire, they can light up the spark of study objective, promote the advancements and become useful talents for the country and society.

To actualize the human-based teaching of professional course, teachers should strengthen the ideology work for the students, and let them know what they can learn, what they can obtain, what they prepare to do, and what they can do in the college stage. Teachers should let students seriously design their self developments, and confirm their future directions and objective, constitute long-term, middle-term and short-term study objectives and detailed plans for their professional knowledge, reasonable distribute their study time and insist on the plan.

\subsection{Profoundly understanding the demand standard of society to talents}

The study of professional course can help undergraduates obtain future employment. Therefore, students should first confirm the demand standard of present society to the talents of materials specialty. At present, most employment enterprises in the materials industry emphasize three basic requirements including educational level, ability and experience. The educational level always indicates talent's basic quality and knowledge level, and the ability can prove talents can comprehensively and flexibly exert knowledge what they learn, and the experience can indicate work experiences and the performance in certain domain. On the other hand, the employment enterprises also emphasize whether the talents possess good human communication and healthy minds and humanistic qualities. The talents only with good human communication abilities can be good at disposal various complex social relationships. To the environment with many uncertain factors, whether management decision or product research and development, will 
always face pressures, frustrations even failures, which needs that talents possess good psychological qualities and healthy psychology. Good humanistic knowledge and qualities can inspire the responsibility and the cultivation of innovational spirit.

In the human-based teaching process of materials specialty, the employment education should go through the professional classroom teaching. In the study process of professional course, when students can profoundly understand the demand standard of present society to the professional talents of materials, they can independently establish the study objective of the professional course and inspire their study enthusiasms for professional course.

\subsection{Grasping scientific study method for professional course}

The materials specialty has enormous cover aspects, and its numerous contents can bring certain difficulty for students, so many students can feel the contents what they study are multifarious and lack in system character. In the human-based teaching process, to improve the study method of professional course is the main measure to solve this problem.

First, students are required to conclude and classify the knowledge what they learn. The materials professional knowledge can be probably generalized as materials science and engineering basic theory knowledge, the methods, intention and measures about materials design, preparation, token and inspection, the designs, production and management of materials machining arts and crafts and equipments, materials testing, production process design, materials nature change and research and development. The professional knowledge is concluded and classified, which can form systematic professional outline. Second, students should "be able to study" professional course. The human-based teaching needs students actively implement exploring and research study, but not only passively accept study. The contents what students need studying should not only be limited in the books, but also be associated with practices. Students need learning to consult materials and know the new developments of the specialty. Students should grasp the inspiration in their studies, exert innovational spirit and realize it. Students need consulting study experiences and feelings to teachers and students, and participating academic communication activities and listening to special topic report and cathedra. Students also need cultivating and finding their own study interests. And "to be able to study" can draw inferences about other cases from one instance, learn independently, carry out the knowledge, and can exploit views and establish ambitions.

\section{Conclusions}

The course teaching of materials specialty which advocates humanity and individuation possesses active function to enhance students' comprehensive quality and promote their comprehensive development, and has important meanings to fulfill social demands for the materials professional talents with high qualities and serve the regional economy. The human-based teaching of materials specialty is still in the budding period, and it still needs relative experts and scholars to research and discuss. To realize the human-based professional course teaching out and out, except for above opinions, we should still consider strengthening the teaching guarantees such as human-based teaching management system and management structure.

\section{References}

Han, Xiangling \& Shen, Hailan. (2006). Human-centered: A Research on The Model with Multiple Targets. Research in Higher Education of Engineering. No.6.

Liuqiang. (2007). Role of Teachers: from Knowledge Transfer to Course Administrator. Research in Higher Education of Engineering. No.1.

Qin, Yiqin. (2005). Explore Human-based Teaching in College Physical Education. Higher Education in Chemical Engineering. No.4.

Xujing. (2005). Explore to Establishing Human-based Teaching Management System. Fujian Higher Education Research. No.4.

Yuan, Xubo \& Shengjing. (2005). The Cultivations of Human-based Quality Education and Innovational Spirit in the Professional Course of Materials Science and Engineering. Research in Higher Education of Engineering (Supplement).

Zhang, Guoying \& Hu, Jiyue. (2005). Study on Human-based Teaching Model in Web-based Education. China Medical Education Technology. No.3.

Zhang, Junjie. (2006). A Study on the Humanized Teaching of Football Class in General College and University. Journal of Qinghai Normal University(Natural Science Edition). No.1.

Zhang, Wenkai. (2006). On Advocating Liberal Education in Engineering Education. Research in Higher Education of Engineering. No.4.

Zou, Jianxin \& Wu, Weigen. (2006). Constructing a Systematized Knowledge of Cultivating Applied Vocational Talents of Materials in Universities. China Metallurgical Education. No.2. 